\title{
No association between common polymorphisms in genes of folate and homocysteine metabolism and the risk of Down's syndrome among French mothers
}

\author{
Abalo Chango ${ }^{1 *}$, Nathalie Fillon-Emery ${ }^{2}$, Clotilde Mircher ${ }^{3}$, Henri Bléhaut ${ }^{3}$, Daniel Lambert ${ }^{4}$, Bernard Herbeth ${ }^{4}$, \\ S. Jill James ${ }^{5}$, Marie-Odile Réthoré ${ }^{3}$ and Jean Pierre Nicolas ${ }^{2}$ \\ ${ }^{1}$ INSERM U 724, Laboratory of Nutritional Genomics, ISAB - Agrohealth, Rue Pierre Waguet, 60026 - Beauvais, France \\ ${ }^{2}$ INSERM U 724, Laboratory of Medical Biochemistry, Faculty of Medicine, Vandoeuvre-lès-Nancy, France \\ ${ }^{3}$ Jerome Lejeune Institute, Paris, France \\ ${ }^{4}$ INSERM U525, Nancy, France \\ ${ }^{5}$ Department of Pediatrics, University of Arkansas for Medical Sciences, Little Rock, AR, USA \\ (Received 10 November 2004 - Revised 23 March 2005 - Accepted 30 March 2005)
}

\begin{abstract}
The cause of the non-disjunction leading to trisomy 21 remains unclear. Recent evidence has suggested that 5,10-methylenetetrahydrofolate reductase (MTHFR) and/or methionine synthase reductase (MTRR) might contribute to the maternal risk of trisomy 21. The purpose of the present study was to analyse these findings among the French population and to investigate whether common polymorphisms in genes of the folate and homocysteine pathway, including the MTHFR 677C $>$ T, MTHFR 1298A $>$ C, the methionine synthase (MTR) 2756A > G, the cystathionine $\beta$-synthase (CBS) 844Ins68 and the reduced folate carrier (RFC-1) 80G > A polymorphisms, contribute to the risk of trisomy 21 . The risk was studied by analysing independent and combined genotypes in 119 case mothers and 119 control mothers. The MTHFR 677T, MTHFR 1298C, MTR2756G, MTRR66G, CBSIns68 + and the RFC-1 $80 \mathrm{G}$ allele frequencies were not significantly different among French case mothers, compared with control mothers. The risk of having a child with trisomy 21 did not appear to be linked to polymorphisms in genes associated with folate and homocysteine metabolism.
\end{abstract}

Down's syndrome: Folate: Polymorphism: Risk

Trisomy 21 or Down's syndrome (DS) is the most common genetic cause of human mental retardation and occurs with a prevalence of 1 in 600-1000 live births. It stems from the failure of chromosome 21 to segregate normally during meiosis (Lejeune et al. 1959). Despite substantial research, the cause of chromosome non-disjunction leading to trisomy 21 remains unclear. Abnormal folate metabolism and a common polymorphism in the folate metabolism gene have been described as possible causes of DS (James et al. 1999). A deficiency in cellular folate and methyl donors have been associated with abnormal DNA methylation, DNA strand breaks and abnormal chromosome segregation (James \& Hobbs, 2002). Although some studies have confirmed an association of certain polymorphisms in genes encoding enzymes of folate metabolism (Hobbs et al. 2000; O'Leary et al. 2002; Grillo et al. 2002; Bosco et al. 2003; da Silva et al. 2005), other studies performed in different ethnic populations have shown inconsistent results (ChadefauxVekemans et al. 2002; Stuppia et al. 2002; Sheth \& Sheth, 2003; Boduroglu et al. 2004).

Since the enzyme 5,10-methylenetetrahydrofolate reductase (MTHFR) acts at the critical metabolic juncture in the folate and homocysteine metabolism, it is interesting to extend studies to known common polymorphisms in other candidate genes encoding proteins that are involved in the folate and homocysteine pathway. We analysed the relationship between MTHFR$677 \mathrm{C}>\mathrm{T}$, MTHFR-1298A $>\mathrm{C}$, methionine synthase (MTR) $2756 \mathrm{~A}>\mathrm{G}$, methionine synthase reductase (MTRR) 66A $>\mathrm{G}$, cystathionine $\beta$-synthase (CBS) 844ins68 and reduced folate carrier (RFC-1) $80 \mathrm{G}>\mathrm{A}$ common polymorphisms and trisomy 21 in the French population, as well as evaluating the possibility of interaction between these genes. We hypothesised that common polymorphisms in key genes involved in folate metabolism may be risk factors for trisomy 21 in some but not all populations. Inconsistencies between studies may be due to genetic heterogeneity between populations.

\section{Subjects and methods}

Participants were either Caucasian mothers of individuals with full trisomy 21 confirmed by karyotype or mothers of normal healthy unrelated subjects. All trisomy were diagnosed as maternally derived and occurred in meiosis I. One hundred and nineteen unselected mothers of individuals with trisomy 21 (case mothers) 
and 119 control mothers were matched for age. Control mothers were enrolled providing that they had not given birth to children with any congenital abnormality (trisomy, neural-tube defect, heart defect, autism and others). Medical records held information about maternal age, pregnancy outcome, previous abortions, miscarriages and number of normal childbirths. The study protocol was approved by the Ethical Committee for Studies on humans at the University Hospital Centre in Nancy, France, and written informed consent was obtained from the participants.

Human genomic DNA was isolated from peripheral blood samples with NucleoSpin Blood Quick Pure (Machery-Nagel, Cergy Pontoise, France). The 677C $>$ T MTHFR variant was identified using PCR followed by restriction enzyme digestion of the amplified product (Frosst et al. 1995). The MTHFR 1298 A > C was measured using the technique described by van der Put $e t$ al. (1998). The common MTR polymorphism that causes an A > G transition at $2756 \mathrm{bp}$, converting an aspartic acid (D-919) into glycine, was identified according to the method of van der Put et al. (1997). The MTRR A $>\mathrm{G}$ transition at $66 \mathrm{bp}$ that converts an isoleucine into a methionine residue was identified using a modified method of Wilson et al. (1999). The common CBS polymorphism that causes an insertion of $68 \mathrm{bp}$ at the 844 position was identified using the method of Tsai et al. (1996). The RFC 80 $\mathrm{G}>$ A polymorphism was identified as described elsewhere using the restriction enzyme $C f o$ I (Chango et al. 2000a).

Differences in allele frequencies and genotype distribution among the different groups were assessed by the $\chi^{2}$ test. A Fisher-Freeman-Halton exact test replaced the $\chi^{2}$ test when at least one expected value was $<5$. A $P$ value $<0.05$ was considered statistically significant.

\section{Results}

The age of case mothers when giving birth to babies with DS was 33.8 (SD 6) years compared with 29.5 (SD 6) years for control mothers. The characteristics of case mothers and controls are given in Table 1 for precedent abortions, miscarriages or number of childbirths. Numbers of case mothers and control mothers grouped by gene genotypes are shown in Table 2. No evidence was found for association between studied polymorphisms and the occurrence of trisomy 21. Concerning the frequency of the MTHFR 677 variant T, $37 \%$ of allele frequency in case mothers were not significantly higher than the frequency in control mothers $(34.4 \%)$. For the MTRR variant $\mathrm{G}$ allele, the frequency was $68 \%$ in case mothers compared with $65 \%$ in control mothers. Analysis of RFC $80 \mathrm{G}>\mathrm{A}$ polymorphism showed no significant difference for the normal allele $\mathrm{G}$ between case mothers $(52.1 \%)$ and control mothers $(55.8 \%)$. The effect of combined genotypes on DS risk was tested by analysing joint distribution of both loci MTHFR
677CT + TT and other genotypes. As shown in Table 3, there was not any significant association between combined MTHFR 677C $>\mathrm{T}$ and other genotypes. A study of the combination of the presence of allele $T$ (MTHFR 677) with the alleles of the four other genes gave similar results and no significant effect. Regarding genotype frequency, the number of individuals with both loci MTHFR 677CT + TT homozygous RFC-1 80AA was higher among case mothers $(23.5 \%)$ than control mothers $(11.3 \%)$ although this did not reach statistical significance. The association MTR/MTTR showed no significant difference between case mothers and control mothers.

\section{Discussion}

Chromosomal non-disjunction is a rare adverse event that occurs during oocyte maturation (meiosis I) or at the time of conception (meiosis II) (McKim \& Hawley, 1995; Lamb et al. 1997). To date, advanced age is the only well-established risk factor. The study by James et al. (1999) was the first to suggest an association between abnormal folate metabolism and the occurrence of trisomy 21 -affected pregnancies in a sample of young mothers. Folate and homocysteine metabolism can be influenced by genetic variants in MTHFR, MTR and MTRR; however, nutritional deficiencies in folic acid or vitamin $\mathrm{B}_{12}$ are often necessary to detect phenotypic expression of these gene variants (Bailey \& Gregory, 1999; Christensen et al. 1999). Common polymorphisms in these genes have been found in some cases to be associated with elevated levels of plasma homocysteine. Concerning MTHFR 677C > T polymorphism, the present results in this French population are in accordance with previous studies conducted by Chadefaux-Vekemans et al. (2002). In their study, mothers did not show a correlation between TT and homocysteine, suggesting that folate intake in France may nullify any effect of the MTHFR TT polymorphism (Chango et al. $2000 \mathrm{~b}$ ). Similar results have also been found in an Italian study conducted by Bosco et al. (2003). Both studies suggested that the Mediterranean diet high in folate could nullify a possible effect of MTHFR polymorphism on DS risk. These results are also consistent with the low frequency of neural-tube defects in both countries (James, 2004).

Polymorphisms in CBS and RFC-1 are known to influence folate and homocysteine metabolism. The present study is the first to analyse RFC-1 common polymorphisms in the risk of having an offspring with trisomy 21. CBS Ins + allelic variant frequency was not significantly different in both groups, even when combined with MTHFR677C $>\mathrm{T}$ polymorphism. However, the present study did show a trend toward an increase in the frequency of the combined homozygote RFC-1 80AA with MTHFR 677 variant T allele (677-(CT + TT)) in DS mothers $(23.5 \%)$ compared with control mothers $(11.3 \%)$.

Table 1. Characteristics of cases and controls: abortion, miscarriage and normal pregnancies

\begin{tabular}{|c|c|c|c|c|c|c|c|c|}
\hline & $n$ & Mean (per mother) ${ }^{\star}$ & $\%$ & $95 \% \mathrm{Cl}$ & $n$ & Mean (per mother) ${ }^{\star}$ & $\%$ & $95 \% \mathrm{Cl}$ \\
\hline Miscarriage & 36 & 0.39 & $30 \cdot 2$ & $26 \cdot 2,45 \cdot 8$ & 43 & 0.60 & $41 \cdot 7$ & $33 \cdot 2,52 \cdot 7$ \\
\hline Normal childbirth & 318 & $2 \cdot 65$ & $100 \dagger$ & NA & 238 & $2 \cdot 31$ & $66 \cdot 3 \dagger$ & 220,255 \\
\hline
\end{tabular}

NA, not applicable.

${ }^{*}$ Mean of the number of occurrences by mother. Some mothers had more than one abortion or miscarriage.

$\dagger \%$ Normal childbirth in comparison with the total number of births. 
Table 2. Genotype and allele frequencies of 5,10-methylenetetrahydrofolate reductase (MTHFR; $677 \mathrm{C}>\mathrm{T}$ and $1298 \mathrm{~A}>\mathrm{C}$ ), methionine synthase (MTR; 2756A > G), methionine synthase reductase (MTRR; 66AG), cystathionine $\beta$-synthase (CBS; 844Ins68) and reduced folate carrier (RFC; $80 \mathrm{G}>\mathrm{A}$ ) gene polymorphisms

\begin{tabular}{|c|c|c|c|c|c|c|c|c|c|c|}
\hline \multirow[b]{3}{*}{ Gene } & \multirow[b]{3}{*}{ Genotype } & \multicolumn{4}{|c|}{ Case mothers } & \multicolumn{4}{|c|}{ Control mothers } & \multirow[b]{3}{*}{$P$ value for genotypes } \\
\hline & & \multicolumn{2}{|c|}{ Genotype } & \multicolumn{2}{|c|}{ Allelic variant } & \multicolumn{2}{|c|}{ Genotype } & \multicolumn{2}{|c|}{ Allelic variant } & \\
\hline & & $n$ & $\%$ & Variant & $\%$ & $n$ & $\%$ & Variant & $\%$ & \\
\hline \multirow[t]{3}{*}{ MTHFR 677CT } & $\mathrm{CC}$ & 43 & $36 \cdot 1$ & & & 49 & $41 \cdot 2$ & & & \\
\hline & CT & 64 & $53 \cdot 8$ & $\mathrm{~T}$ & 37 & 58 & $48 \cdot 7$ & $\mathrm{~T}$ & $34 \cdot 4$ & $0.51^{*}$ \\
\hline & TT & 12 & $53 \cdot 8$ & & & 12 & $10 \cdot 1$ & & & \\
\hline \multirow[t]{3}{*}{ MTHFR 1298AC } & AA & 59 & $49 \cdot 6$ & & & 52 & $43 \cdot 3$ & & & \\
\hline & $\mathrm{AC}$ & 49 & $41 \cdot 2$ & C & $29 \cdot 8$ & 56 & $46 \cdot 6$ & $\mathrm{C}$ & $33 \cdot 3$ & $0.51^{*}$ \\
\hline & $\mathrm{CC}$ & 11 & $9 \cdot 2$ & & & 12 & 10 & & & \\
\hline \multirow[t]{3}{*}{ MTR 2756AG } & AA & 84 & $70 \cdot 6$ & & & 87 & $72 \cdot 5$ & & & \\
\hline & $A G$ & 33 & $27 \cdot 7$ & G & $15 \cdot 6$ & 32 & $26 \cdot 6$ & $\mathrm{G}$ & $14 \cdot 2$ & $0.87 \dagger$ \\
\hline & GG & 2 & $1 \cdot 7$ & & & 1 & 0.8 & & & \\
\hline \multirow[t]{3}{*}{ MTRR 66AG } & $\mathrm{AA}$ & 5 & $4 \cdot 2$ & & & 6 & 5 & & & \\
\hline & $A G$ & 66 & $55 \cdot 5$ & $\mathrm{G}$ & 68 & 72 & 60 & G & 65 & $0.75 \dagger$ \\
\hline & GG & 48 & $40 \cdot 3$ & & & 42 & 35 & & & \\
\hline \multirow[t]{2}{*}{ CBS 844Ins68 } & Ins $-/-$ & 109 & $91 \cdot 6$ & & & 106 & $88 \cdot 3$ & & & \\
\hline & $\begin{array}{l}\text { Ins }-/+ \\
\text { Ins }+/+\end{array}$ & 10 & 8.4 & Ins + & 8.4 & $\begin{array}{r}13 \\
1\end{array}$ & $\begin{array}{r}10 \cdot 8 \\
0.8\end{array}$ & Ins + & $6 \cdot 25$ & $0.58 \dagger$ \\
\hline \multirow[t]{3}{*}{ RFC 80GA } & AA & 24 & $20 \cdot 2$ & & & 16 & 17 & & & \\
\hline & GA & 66 & 55.5 & G & $52 \cdot 1$ & 52 & $55 \cdot 3$ & G & $55 \cdot 8$ & $0.22^{*}$ \\
\hline & GG & 29 & $24 \cdot 4$ & & & 26 & $27 \cdot 6$ & & & \\
\hline
\end{tabular}

${ }^{*} \mathrm{~A} \chi^{2}$ test was used when no expected value was $<5$

†A Fisher-Freeman-Halton exact test was use when at least one expected value was $<5$.

Among participants of our previous random study (Chango et al. $2000 a$ ), homozygous RFC-1 genotypes were $21.9 \%$ 80AA and $27.2 \%$ 80GG. Homozygous RFC-1 80AA and MTHFR 677TT had lower erythrocyte folate level than homozygous MTHFR 677TT alone or combined homozygous RFC-1 80AA and MTHFR 677CC. Morin et al. (2003) have recently shown that the combination of RFC-1 $80 \mathrm{G}>\mathrm{A}$ polymorphism and low erythrocyte folate was due to a significant $4 \cdot 6$-fold increase in spina bifida. It is interesting to note the hypothesis that, in some genetic determinants of folate metabolism, a common pathway may exist for neural tube defects and trisomy 21 (Al-Gazali et al. 2001; Barkai et al. 2003; Guéant et al. 2003).

Based on evidence that abnormal one-carbon metabolism can lead to abnormal chromosomal segregation, Bosco et al. (2003) observed high levels of plasma total homocysteine in mothers with polymorphism in MTHFR 677C $>\mathrm{T}$ and MTRR 66A $>\mathrm{G}$ genes. This was found to be associated with an increased risk of having a child with trisomy 21 . In the present study, because

Table 3. Combined 5,10-methylenetetrahydrofolate reductase (MTHFR) 677 (CT + TT) genotypes and other gene polymorphisms interaction

\begin{tabular}{|c|c|c|c|c|c|c|c|c|c|c|c|c|}
\hline \multirow[b]{3}{*}{ Gene } & \multirow[b]{3}{*}{ Genotype } & \multicolumn{8}{|c|}{ MTHFR 677: presence of allele T $(\mathrm{CT}+\mathrm{TT})$} & \multirow[b]{3}{*}{ P Genotypes* } & & \\
\hline & & \multicolumn{4}{|c|}{ Case mothers } & \multicolumn{4}{|c|}{ Control mothers } & & & \\
\hline & & $n$ & $\%$ & Allele & $\%$ & $n$ & $\%$ & Allele & $\%$ & & Genotypes & Alleles \\
\hline \multirow[t]{2}{*}{ MTHFR $1298 \mathrm{~A}>\mathrm{C}$} & AA & 46 & $61 \cdot 1$ & $A$ & $80 \cdot 2$ & 42 & $60 \cdot 4$ & $A$ & $79 \cdot 7$ & 0.64 & 0.79 & 0.57 \\
\hline & $\mathrm{CC}$ & 0 & 0 & & & 1 & 1.8 & & & & & \\
\hline \multirow[t]{3}{*}{ MTR $2756 \mathrm{~A}>\mathrm{G}$} & AA & 50 & $66 \cdot 2$ & A & 81.5 & 52 & $74 \cdot 3$ & A & $87 \cdot 1$ & 0.37 & 0.33 & 0.43 \\
\hline & $A G$ & 24 & $30 \cdot 9$ & $\mathrm{G}$ & $18 \cdot 4$ & 18 & $25 \cdot 7$ & $\mathrm{G}$ & $12 \cdot 8$ & & & \\
\hline & GG & 2 & $2 \cdot 9$ & & & 0 & 0 & & & & & \\
\hline \multirow[t]{3}{*}{ MTRR $66 \mathrm{~A}>\mathrm{G}$} & $\mathrm{AA}$ & 4 & $5 \cdot 9$ & A & $34 \cdot 8$ & 5 & $7 \cdot 1$ & A & $37 \cdot 8$ & 0.99 & 0.79 & 0.66 \\
\hline & $A G$ & 45 & $58 \cdot 8$ & $\mathrm{G}$ & $65 \cdot 1$ & 43 & $61 \cdot 4$ & $\mathrm{G}$ & $62 \cdot 1$ & & & \\
\hline & GG & 27 & $35 \cdot 3$ & & & 22 & $31 \cdot 4$ & & & & & \\
\hline CBS 844Ins68 & Ins $+1+$ & 67 & $88 \cdot 2$ & $\operatorname{lns}^{+}$ & $94 \cdot 1$ & 63 & 90 & $\operatorname{lns}^{+}$ & $94 \cdot 3$ & 0.52 & 0.50 & 0.99 \\
\hline \multirow[t]{3}{*}{$\mathrm{RFC}-180 \mathrm{G}>\mathrm{A}$} & GG & 19 & $25 \cdot 0$ & $\mathrm{G}$ & $50 \cdot 6$ & 20 & $28 \cdot 3$ & $\mathrm{G}$ & $58 \cdot 6$ & 0.22 & $0 \cdot 17$ & 0.31 \\
\hline & $\mathrm{GA}$ & 39 & $51 \cdot 5$ & $A$ & $49 \cdot 3$ & 42 & $60 \cdot 4$ & $A$ & $41 \cdot 0$ & & & \\
\hline & $\mathrm{AA}$ & 18 & $23 \cdot 5$ & & & 8 & $11 \cdot 3$ & & & & & \\
\hline
\end{tabular}

MTR, methionine synthase; MTRR, methionine synthase reductase; CBS, cystathionine $\beta$-synthase; RFC, reduced folate carrier.

${ }^{*} \chi^{2}$ Test.

†Fisher-Freeman-Halton exact test. 
blood samples were not available at the birth of trisomy 21 individuals, blood folate or homocysteine was not taken into account. One of the major unanswered issues we must address concerning folate deficiency and chromosome hypomethylation in non-disjunction is the role of homocysteine during meisis I (or meiosis II) stages. Case mothers in the present study were aged from 18 to 46 years (mean 33.8 (SD 6) years) at the time of DS pregnancy outcome. Homocysteine increased secondary to folate might accelerate age-related phenomena causing the delivery of abnormal oocytes, particularly among mothers under 35 years. The diagnosis of specific genotypes in terms of specific metabolic biomarkers such as blood folate and/ or homocysteine would increase the sensitivity to detect an impact of genotype on the risk of having a trisomy 21 child.

In conclusion, we did not find an association between studied single gene polymorphisms and the occurrence of trisomy 21 . A limitation of the present study is the absence of homocysteine and erythrocyte folate data, to increase the sensitivity to detect a correlation between genotype and risk of trisomy 21 .

\section{Acknowledgements}

The present study was supported by a grant from the Fondation Jerôme Lejeune. The authors thank all those who have participated in the study, the Jérome Lejeune Institute and the Centre de Medecine Preventive in Nancy; a special acknowledgement is given to Bérangère Marie for her statistical assistance.

\section{References}

Al-Gazali LI, Padmanabhan R, Melnyk S, et al. (2001) Abnormal folate metabolism and genetic polymorphism of the folate pathway in a child with Down syndrome and neural tube defect. Am J Med Genet 103, $128-132$.

Bailey LB \& Gregory JF III (1999) Polymorphisms of methylenetetrahydrofolate reductase and other enzymes: metabolic significance, risks, and impact on folate requirement. J Nutr 129, 919-922.

Barkai G, Arbuzova S, Berkenstadt M, Heifetz S \& Cuckle H (2003) Frequency of Down's syndrome and neural-tube defects in the same family. Lancet 361, 1331-1335.

Boduroglu K, Alanay Y, Koldan B \& Tuncbilek E (2004) Methylenetetrahydrofolate reductase polymorphisms as maternal risk for Down syndrome in Turkey. Am J Med Genet 15, 5-10.

Bosco P, Gueant-Rodriguez RM, Anello G, Barone C, Namour F, Caraci F, Romano A, Romano C \& Gueant JL (2003) Methionine synthase (MTR) 2756 (A > G) polymorphism, double heterozygosity methionine synthase 2756 AG/methionine synthase reductase (MTRR) 66 AG, and elevated homocysteinemia are three risk factors for having a child with Down syndrome. Am J Med Genet 121A, 219-224.

Chadefaux-Vekemans B, Coude M, Muller F, Oury JF, Chabli A, Jais J \& Kamoun P (2002) Methylenetetrahydrofolate reductase polymorphism in the etiology of Down syndrome. Pediatr Res 51, 766-767.

Chango A, Emery-Fillon N, de Courcy GP, Lambert D, Pfister M, Rosenblatt DS \& Nicolas JP (2000a) A polymorphism (80G- $>$ A) in the reduced folate carrier gene and its associations with folate status and homocysteinemia. Mol Genet Metab 70, 310-315.

Chango A, Potier de Courcy G, Boisson F, et al. (2000b) 5,10-Methylenetetrahydrofolate reductase (MTHFR), common mutations, folate status, and plasma homocysteine in healthy French adults of the SU.VI.MAX cohort. Br J Nutr 84, 891-896.

Christensen B, Arbour L, Tran P, Leclerc D, Sabbaghian N, Platt R, Gilfix BM, Rosenblatt DS, Gravel RA, Forbes P \& Rozen R (1999) Genetic polymorphisms in methylenetetrahydro-folate and methionine synthase, folate levels in red blood cells, and risk of neural tube defects. Am J Med 84, 151-157.

da Silva LRJ, Vergani N, Galdieri LC, Porto MPR, Longhitano SB, Brunoni D, d'Almeida V \& Perez ABA (2005) Relationship between polymorphisms in genes involved in homocysteine metabolism and maternal risk for Down syndrome in Brazil. Am J Med Genet 135, 263-267.

Frosst P, Blom HJ, Milos R, et al. (1995) A candidate genetic risk factor for vascular disease: a common mutation in methylenetetrahydrofolate reductase. Nat Genet 10, 111-113.

Grillo LB, Acacio GL, Barini R, Pinto W Jr \& Bertuzzo CS (2002) Mutations in the methylenetetrahydrofolate reductase gene and Down syndrome. Cad Saude Publica 18, 1795-1797.

Guéant JL, Rodriguez-Guéant RM, Anello G, Bosco P, Brunaud L, Romano C, Ferri R, Romano A, Candoto M \& Namour B (2003) Genetic determinants of folates and vitamin $\mathrm{B}_{12}$ metabolisms: a common pathway in neural tube defect and Down syndrome. Clin Chem Lab Med 41, 1473-1477.

Hobbs CA, Sherman SL, Yi P, Hopkins SE, Torfs CP, Hine RJ, Pogribna M, Rozen R \& James SJ (2000) Polymorphisms in genes involved in folate metabolism as maternal risk factors for Down syndrome. Am J Hum Genet 67, 623-630.

James SJ (2004) Maternal metabolic phenotype and risk of Down syndrome: beyond genetics. Am J Med Genet 127A, 1-4.

James SJ \& Hobbs C (2002) Folate deficiency and molecular determinants of chromosome instability. In Folate and Human Development, pp. 43-69 [E Massaro and JM Rogers, editors]. Totowa, NJ: Humana Press.

James SJ, Pogribna M, Pogribny IP, et al. (1999) Abnormal folate metabolism and mutation in the methylenetetrahydrofolate reductase gene may be maternal risk factors for Down syndrome. Am J Clin Nutr 70, 495-501.

Lamb NE, Feingold E, Savage A, et al. (1997) Characterization of susceptible chiasma configurations that increase the risk for maternal nondisjunction of chromosome 21. Hum Mol Genet 6, 1391-1399.

Lejeune J, Gautier M \& Turpin MR (1959) Etude des chromosomes somatiques de neuf enfants mongoliens (Study of the somatic chromosomes of nine mongol children). C R Acad Sci (Paris) 248, 1721.

McKim KS \& Hawley RS (1995) Chromosomal control of meiotic cell division. Science 270, 1595-1601.

Morin I, Devlin AM, Leclerc D, Sabbaghian N, Halsted CH, Finnell R \& Rozen R (2003) Evaluation of genetic variants in the reduced folate carrier and in glutamate carboxypeptidase II for spina bifida risk. Mol Genet Metab 79, 197-200.

O'Leary VB, Parle-McDermott A, Molloy AM, Kirke PN, Johnson Z, Conley M, Scott JM \& Mills JL (2002) MTRR and MTHFR polymorphism: link to Down syndrome? Am J Med Genet 107, 151-155.

Sheth JJ \& Sheth FJ (2003) Gene polymorphism and folate metabolism: a maternal risk factor for Down syndrome. Indian Pediatr 40, 115-123.

Stuppia L, Gatta V, Gaspari AR, Antonucci I, Morizio E, Calabresse G \& Palka G (2002) C677T mutation in the 5,10-MTHFR gene and risk of Down syndrome in Italy. Eur J Hum Genet 10, 388-390.

Tsai MY, Bignell M, Schwichtenberg K \& Hanson NQ (1996) High prevalence of a mutation in the cystathionine beta-synthase gene. Am J Hum Genet 59, 1262-1267.

van der Put NM, Gabreels F, Stevens EM, Smeitink JA, Trijbels FJ, Eskes TK, van den Heuvel LP \& Blom HJ (1998) A second common mutation in the methylenetetrahydrofolate reductase gene: an additional risk factor for neural-tube defects? Am J Hum Genet 62, 1044-1051.

van der Put NM, van der Molen EF, Kluijtmans LA, Heil SG, Trijbels JM, Eskes TK, van Oppenraaij-Emmerzaal D, Banerjee R \& Blom HJ (1997) Sequence analysis of the coding region of human methionine synthase: relevance to hyperhomocysteinaemia in neural-tube defects and vascular disease. Qjm 90, 511-517.

Wilson A, Platt R, Wu Q, Leclerc D, Christensen B, Yang H, Gravel RA \& Rozen R (1999) A common variant in methionine synthase reductase combined with low cobalamin (vitamin B12) increases risk for spina bifida. Mol Genet Metab 67, 317-323. 